This PDF file of your paper in Recent Advances in Ageing and Sexing Animal Bones belongs to the publishers Oxbow Books and it is their copyright.

As author you are licenced to make up to 50 offprints from it, but beyond that you may not publish it on the World Wide Web or in any other form. 


\section{TO AT}

Recent Advances in Ageing and Sexing Animal Bones 
For Vasili and Marilena 
Proceedings of the 9th Conference of the International Council of Archaeozoology, Durham, August 2002

Series Editors: Umberto Albarella, Keith Dobney and Peter Rowley-Conwy

\section{Recent Advances in Ageing and Sexing Animal Bones}

Edited by

Deborah Ruscillo

Oxbow Books 
Published by

Oxbow Books, Park End Place, Oxford OX1 1HN

(C) Oxbow Books and the individual authors 2006

ISBN $9781842171226 \quad 1842171224$

A CIP record for this book is available from The British Library

This book is available direct from Oxbow Books, Park End Place, Oxford OX1 1HN

(Phone: 01865-241249; Fax: 01865-794449)

and

The David Brown Book Company

PO Box 511, Oakville, CT 06779, USA

(Phone: 860-945-9329; Fax: 860-945-9468)

and

via our website

www.oxbowbooks.com

Cover image: Ursus americanus baculum, mandible and innominate, photo taken by Haskel Greenfield

Printed in Great Britain at

Antony Rowe, Chippenham 


\section{Contents}

Preface vii

Umberto Albarella, Keith Dobney and Peter Rowley-Conwy

Acknowledgments ix

\section{Introduction}

1. Vertebrate Demography by Numbers: Age, Sex, and Zooarchaeological Practice 1 T. P. O'Connor

\section{Part I. New Approaches to Ageing and Sexing}

2. Using Osteohistology for Ageing and Sexing ....... 9

K. Dammers

3. A Method to Estimate the Ages at Death of Red Deer (Cervus elaphus) and Roe Deer (Capreolus capreolus) from Developing Mandibular Dentition and its Application to Mesolithic NW Europe 40 Richard J. Carter

4. The Table Test: a Simple Technique for Sexing Canid Humeri 62 Deborah Ruscillo

5. Sexing Fragmentary Ungulate Acetabulae 68 Haskel Greenfield

\section{Part II. Testing Existing Methods of Ageing}

6. Reconciling Rates of Long Bone Fusion and Tooth Eruption and Wear in Sheep (Ovis) and Goat (Capra) 87 M. A. Zeder

7. Accuracy of Age Determinations from Tooth Crown Heights: a Test Using an Expanded Sample of Known Age Red Deer (Cervus Elaphus)

T. E. Steele

8. Methodological Problems and Biases in Age Determinations: a View from the Magdalenian J. G. Enloe and E. Turner

9. A Bayesian Approach to Ageing Sheep/Goats from Toothwear.... A. R. Millard

\section{Part III. Studies in Ageing by Dental Eruption and Attrition}

10. Tooth Eruption and Wear Observed in Live Sheep from Butser Hill, the Cotswold Farm Park and Five Farms in the Pentland Hills, UK

G. G. Jones

11. Determining the Age of Death of Proboscids and Rhinocerotids from Dental Attrition S. Louguet

12. Tooth Wear in Wild Boar (Sus Scrofa) 


\section{Part IV. Applications of Osteometrics and Epiphyseal Fusion}

13. Phenotype and Age in Protohistoric Horses: a Comparison Between Avar and Early Hungarian Crania 204 L. Bartosiewicz

14. Documenting the Channel Catfish Population Exploited by the Prehistoric Inhabitants of the Station-3-avant Site at Pointe-du-Buisson, Southern Québec (Canada)

M.-E. Brodeur

15. Epiphyseal Fusion in the Postcranial Skeleton as an Indicator of Age at Death of European Fallow Deer (Dama dama dama, Linnaeus, 1758)

R. F. Carden and T. J. Hayden

16. Size Variability in Roman Period Horses from Hungary

K. Lyublyanovics

\section{Part V. Studies in Sexual Dimorphism}

17. Environment, Body Size and Sexual Dimorphism in Late Glacial Reindeer J. Weinstock

18. Sexual Dimorphism in the Postcranial Skeleton of European Fossil Elephants 254 L. Sedláčková 


\section{Preface}

\section{Umberto Albarella, Keith Dobney and Peter Rowley-Conwy}

This book is one of several volumes which form the published proceedings of the 9th meeting of the International Council of Archaeozoology (ICAZ), which was held in Durham (UK) 23rd-28th August 2002. ICAZ was founded in the early ' 70 s and has ever since acted as the main international organisation for the study of animal remains from archaeological sites. The main international conferences are held every four years, and the Durham meeting the largest ever - follows those in Hungary, the Netherlands, Poland, England (London), France, USA, Germany and Canada. The next meeting will be held in Mexico in 2006. The Durham conference - which was attended by about 500 delegates from 46 countries - was organised in 23 thematic sessions, which attracted, in addition to zooarchaeologists, scholars from related disciplines such as palaeoanthropology, archaeobotany, bone chemistry, genetics, mainstream archaeology etc.

The publication structure reflects that of the conference, each volume dealing with a different topic, be it methodological, ecological, palaeoeconomic, sociological, historical or anthropological (or a combination of these). This organisation by theme rather than by chronology or region, was chosen for two main reasons. The first is that we wanted to take the opportunity presented by such a large gathering of researchers from across the world to encourage international communication, and we thought that this could more easily be achieved through themes with world-wide relevance. The second is that we thought that, by tackling broad questions, zooarchaeologists would be more inclined to take a holistic approach and integrate their information with other sources of evidence. This also had the potential of attracting other specialists who shared an interest in that particular topic. We believe that our choice turned out to be correct for the conference, and helped substantially towards its success. For the publication there is the added benefit of having a series of volumes that will be of interest far beyond the restricted circle of specialists on faunal remains. Readers from many different backgrounds, ranging from history to zoology, will certainly be interested in many of the 14 volumes that will be published.

Due to the large number of sessions it would have been impractical to publish each as a separate volume, so some that had a common theme have been combined. Far from losing their main thematic focus, these volumes have the potential to attract a particularly wide and diverse readership. Because of these combinations (and because two other sessions will be published outside this series) it was therefore possible to reduce the original 24 sessions to 14 volumes. Publication of such a series is a remarkable undertaking, and we are very grateful to David Brown and Oxbow Books for agreeing to produce the volumes.

We would also like to take this opportunity to thank the University of Durham and the ICAZ Executive Committee for their support during the preparation of the conference, and all session organisers - now book editors - for all their hard work. Some of the conference administrative costs were covered by a generous grant provided by the British Academy. Further financial help came from the following sources: English Heritage, Rijksdienst voor het Oudheidkundig Bodemonderzoek (ROB), County Durham Development Office, University College Durham, Palaeoecology Research Services, Northern Archaeological Associates, Archaeological Services University of Durham (ASUD), and NYS Corporate Travel. Finally we are extremely grateful for the continued support of the Wellcome Trust and Arts and Humanities Research Board (AHRB) who, through their provision of Research Fellowships for Keith Dobney and Umberto Albarella, enabled us to undertake such a challenge.

The present volume publishes the proceedings of the session 'Ageing and Sexing', which was among the first to be proposed for ICAZ 2002 and ended up being one of the strongest and best attended. This was in large part due to Deborah Ruscillo's excellent organisational skills, but also to the inherent interest and appropriateness of this subject for an ICAZ conference. Whether we study material from Argentina or Japan, from the Palaeolithic or the medieval 
period, we still need to deal with the issue of ageing and sexing animal bones. A methodological session may be of little interest outside the field of zooarchaeology, but this is compensated for by the fact that all animal bone specialists will be interested in it. Initially Deborah wanted simply to find the best venue to present her interesting new method of sexing mammal bones through shape analysis. However, here was an opportunity to be more ambitious and organise a whole session dedicated to sexing and ageing studies. Things went ahead as planned and this book represents the culmination of almost three years of work, begun with a cosy conversation in the warm environment of the Ruscillo/Cosmopoulos home in Winnipeg (as the external temperature approached minus $30^{\circ} \mathrm{C}$ !).

The publication in 1982 of the volume "Ageing and sexing animal bones from archaeological sites", edited by Bob Wilson, Caroline Grigson and Sebastian Payne, represented a milestone in the development of zooarchaeological studies, and the book is, unsurprisingly, one of the most cited publications in zooarchaeology. Since then, as Terry O'Connor highlights in his introduction to the present volume, much more work has been done in refining ageing and sexing methods and in improving our understanding of body development and sexual variation in the vertebrate skeleton. However, so far zooarchaeologists are still by and large adopting ageing and sexing methods that are pre- rather than post- 1982. The challenge of this book is therefore not just to add more information, but also to persuade zooarchaeologists that the time is ripe for experimenting with new methods and for analysing data by taking into account the substantial new advances that this discipline has produced in more recent years. Only time will tell if this volume will have achieved this ambitious goal, but whatever the case, we have little doubt that it will represent an indispensable tool for zooarchaeologists worldwide.

Final special thanks must go to Vasili and Marilena Cosmopoulos (Deborah's son and daughter), who had the good grace to be born during the final stages of the editing of this volume. We could not have expected a better omen for the success of the book. 


\section{Acknowledgments}

These proceedings are a direct result of the teamwork and collegiality of the authors involved. Always polite and accommodating, the participants of the Ageing and Sexing Session were a pleasure to work with, and I thank them for their cooperation and their contributions to methodology in zooarchaeology. The participants of the session also acted as referees of the published proceedings; each participant reviewed two papers submitted for publication to ensure the quality and accuracy of the information presented herein. For the sake of keeping costs low, raw data for the various studies presented in this volume could not be published. The authors are happy to provide raw data from their research upon request (addresses provided at the end of each chapter).

The session would not have been such a success were it not for the tireless support and direction of the conference organizers. This publication was made possible by these same individuals who also bravely took on the series editing and organization after the conference ended. On behalf of all the participants of the Ageing and Sexing Session, I wish to express our appreciation for the commitment of Umberto Albarella, Keith Dobney, Peter RowleyConwy and Deborah Jaques for the conference preparations and publication series organization. I would also like to thank Simon Davis and Caroline Grigson for chairing the morning and afternoon sections of the ageing and sexing colloquium, and also for acting as referees for some papers submitted here.

Travel and accommodation grants for the participants were supplied thanks to generous funding from the Institute for Aegean Prehistory (INSTAP). We are grateful for their support and their broad vision of archaeological research. INSTAP is one of the few organizations that realize the potential of zooarchaeological studies in the quest of studying ancient peoples. 


\title{
9. A Bayesian Approach to Ageing Sheep/Goats from Toothwear
}

\author{
A. R. Millard
}

For the last 20 years the human osteology literature has contained discussions of statistical problems with traditional skeletal ageing methods, which lead to "age mimicry", where the estimated age structure partly resembles that of the reference population. This paper discusses how these problems also apply to animal ageing techniques and proposes a method to overcome them in the case of ageing of sheep and goats by toothwear. A form of transition analysis is developed, using the data of Deniz and Payne as a reference population. The method is tested with other published known age animals. Payne's A-I mandible wear stages are investigated and found to underestimate variability. The method is applied to the large assemblage of sheep and goat mandibles from Arene Candide, Italy to illustrate the extent of uncertainty in estimating survivorship curves. The limitations of the current model and possible improvements are discussed.

\section{Introduction}

Ageing studies of both humans and animals rely on similar sets of changes in teeth and bones, yet there is little crossover between the zooarchaeological literature and the human osteoarchaeological literature on this topic. In the last 20 years, discussions of any method of ageing human skeletal material have been incomplete without reference to the important paper of BocquetAppel and Masset (1982), and the subsequent debate in the literature on how one estimates an age from an observed osteological state (Hoppa and Vaupel 2002). However, despite its relevance and importance I have been unable to find any mention of this paper in the zooarchaeological literature (for example, there are no citations in Environmental Archaeology, animal bone papers in International Journal of Osteoarchaeology (1995-2002), or the proceedings of the 1988 and 1994 ICAZ conferences in Anthropozoologica). This paper seeks to improve animal age estimation by bringing some of the cutting edge statistical methodology of human osteology to bear on animal ageing problems. It adopts a method known as 'transition analysis' (Boldsen et al. 2002; Millard and Gowland 2002) to estimate the age of sheep and goats from their toothwear, using the data of Deniz and Payne (1982) as a reference population. This approach is applied to the sheep and goat toothwear data from Arene Candide (Rowley-Conwy 1997) in order to obtain kill profiles which include estimates of the uncertainty due to both the ageing technique and sampling error.

\section{The Statistics of Ageing Techniques}

Almost all skeletal ageing methods (both animal and human) have a common basis in their construction. The age indicator is observed in a modern reference population to establish its variation with age, and this information is then used to estimate the age of an archaeological target population. However, a number of studies of the past two decades have demonstrated that, unless particular care is taken, the age distribution of the target population will be affected by the age structure of the reference population (e.g. Bocquet-Appel and Masset 1982, 1985, 1996; Konigsberg and Frankenberg 1994; Konigsberg et al. 1997; Lucy et al. 1996; Aykroyd et al. 
1997, 1999). This effect is termed "age mimicry". The key points that have been established are:

1. that age mimicry is a result of the inappropriate use of likelihood-based statistical methods to estimate the age of individuals (Konigsberg and Frankenberg 1992; Aykroyd et al. 1999), and is only absent when the reference population and target population have the same age structure, or the reference population is carefully constructed to have a uniform distribution of ages;

2. that the extent of age mimicry is inversely related to the correlation between the indicator and age (Aykroyd et al. 1997), that is, the more closely changes in the indicator are related to age, the less age mimicry will occur (and vice versa);

3. that the ages of individuals may be estimated reliably if Bayes' theorem is used to incorporate the prior probability of age based on the age structure of the population from which the individual is drawn (Konigsberg and Frankenberg 1994; Lucy et al. 1996);

4. that given (3), if we do not know a priori the characteristics of the population, then the problem is how to estimate the age structure of the population before (or simultaneously with) estimating the ages of the individuals (Hoppa and Vaupel 2002).

Ageing techniques for animal remains have proceeded on essentially the same basis as human ageing techniques traditionally did. They are therefore subject to the problems described above and also suffer from a lack of a full consideration of uncertainty:

"nearly all methods of ageing in current use do not make proper use of the statistical nature of age estimates... age estimation from one or more skeletal traits is a process of generating the distribution of possible chronological ages....by throwing out distributional information around the mean or median age, we gain a false sense of statistical power about statements based on that age" (Konigsberg and Holman 1999, 265).

Traditional age estimation methods tend to treat ages as though they are exact, rather than a distribution of possible ages. However, no ageing method can produce exact chronological ages because individuals vary in the age of attainment of a given developmental or degenerational stage. Even if an indicator was perfectly correlated with chronological age and all variation eliminated, the use of an ordinal scoring method (as for tooth development and toothwear) still yields a distribution of ages rather than an exact age because individuals enter a given stage and remain there for some period of time (Konigsberg and Holman 1999).

Some zooarchaeological workers have recognised the uncertainty of ageing and compensated for it by using broad categories such as "immature" (e.g. O'Connor
1991) or simply wear stages (e.g. Jones 1992). Even these procedures are problematic. Use of broad age categories takes the detailed age structure evidenced in toothwear and other skeletal indicators and discards it because the detail is difficult to interpret. Use of the indicator states alone allows comparison between assemblages for similar or dissimilar survival patterns, but does not allow these patterns to be related to theoretical concepts such as Payne's (1973) milk, meat and wool survivorship curves. In recent years in order to address these problems, there has been a move in human osteoarchaeology towards the use of Bayes' Theorem for age estimation. For this purpose, Bayes' theorem may be represented by the following equation:

\begin{tabular}{|c|c|c|}
\hline $\begin{array}{l}\text { posterior probability } \\
\text { of having age } a \\
\text { given the observed } \\
\text { osteological state }\end{array}$ & $\begin{array}{l}\text { likelihood of being } \\
\propto \text { in the observed } \\
\text { state, } c \text {, if we knew } \\
\text { the age was } a\end{array}$ & $\begin{array}{l}\text { prior } \\
\text { probability } \\
\text { of having } \\
\text { age } a\end{array}$ \\
\hline
\end{tabular}

$$
\mathrm{p}(a \mid c) \quad \propto \quad \mathrm{p}(c \mid a) \quad \times \quad \mathrm{p}(a)
$$

where $a=$ age, and $c=$ indicator (e.g. toothwear stage)

Several age indicators (e.g. the state of different teeth) can easily be combined if we assume that while they are conditional on age, they are independent of each other given age. This is advantageous when estimating age from multiple variables and automatically weighs each indicator according to the probability distribution, eliminating the dubious process of imposing weights, or worse still, assuming that each indicator contributes equally (Lucy 1997).

In the application of Bayesian statistics to palaeodemography, the choice of prior is crucial. For example, Lucy (1997) adopts a prior based on the age distribution of the reference sample, but this incorporates a bias inherent in regression analysis, and better priors can be chosen. In contrast, Chamberlain (2000) compares the adoption of a uniform prior on age and a prior based on model life tables. A further development has been that of estimating the structure of ages in the population from the distribution of indicator states in the population (Love and Müller 2002; Holman et al. 2002) using the principle of maximum likelihood to obtain a single age structure which can be used as a prior for the estimation of individual ages. However, there is clearly going to be some uncertainty about what age structure, and Konigsberg and Herrman (2002) take the further step of considering the distribution of probabilities of age structures given by the likelihood in their age estimation. In this paper, I take a different approach by including a Bayesian (rather than likelihood) consideration of the distribution of age structures. This extends the method of Chamberlain (2000) by considering a prior range of age structures, themselves with varying probabilities, based on theoretical considerations, in this case Payne's idealised kill patterns for milk and wool economies. 


\section{Materials and Methods}

\section{Data}

Several sets of previously published data are analysed in this paper. First, the data of Deniz and Payne (1982) on tooth eruption and wear in Turkish Angora goats are analysed as a reference population. Their study is by far the largest on tooth eruption and wear in sheep or goats, and the data are published fully enough to allow reanalysis. Deniz and Payne analysed their data to estimate transition ages and their variability assuming that the cumulative percentage of individuals having attained or passed a particular stage was log-normally distributed on an age scale starting at birth. Here I assume that the cumulative percentages are log-logistically distributed with respect to age from conception. A logistic distribution is used in preference to a normal distribution because:

a. it has heavier tails which help to counter the problem of underestimating uncertainty by assuming all of an individual's tooth eruption and wear states are independent given the animal's age;

b. it is computationally more stable in the software package used (WinBUGS) than the common alternative cumulative normal distribution.

Gestation in sheep is 147 days (Blaxter 1980, 9), and I assume the same for goats, which have gestation of about five months (Dahl and Hjort 1976, 92). Any difference will have little influence on estimated ages apart from those of the very youngest animals. The use of data on goats to produce an ageing technique for sheep needs some justification. The available data on tooth eruption timing in sheep and goats (summarised in Hillson 1986, 202-203) suggests little difference between the species, but see the discussion in Jones (this volume) for a consideration of possible differences. The tooth morphology is so similar that although the species can be distinguished on the basis of the cheek teeth when fully erupted and not heavily worn (Payne 1985; Halstead et al. 2002), the same eruption-attrition schemes are necessarily used for both (Hillson 1986, 202). "This leaves the question of applying data from Turkish goats to archaeological sheep: the close phylogenetic relationship of the species, and the general similarity of dental development in sheep and goats, give some reason to accept the results of such a comparison." (Moran and O’Connor 1994, 269)

Secondly, the ageing method is tested on the data from known age sheep presented by O'Connor (1998), and finally it is applied to the recorded toothwear of sheep and goat mandibles from the Early Neolithic $(n=50)$ and Middle Neolithic I ( $\mathrm{n}=283$ ) levels at Arene Candide, Italy (Rowley-Conwy 1997). The latter two data-sets consist, as in many archaeological assemblages, of data on the cheek teeth only, i.e. the deciduous fourth premolar and its replacement the permanent fourth premolar, and the first, second and third molars (denoted dp4, P4, M1, M2 and M3 respectively). Therefore, only these teeth from the Deniz and Payne (1982) data are included in the first analysis.

\section{Mathematical/Statistical models}

As tooth eruption and wear are recorded as a series of ordinal stages, I adopt a model based on analysing the threshold age of (or age of transition to) a stage, and the variability between individuals of that threshold, to obtain the probability that a tooth is in a particular stage. The model described below is very similar to that developed by Millard and Gowland (2002) for the analysis of tooth development and wear in humans, and is a form of transition analysis analogous to those of Boldsen et al. (2002) and Holman et al. (2002) for other ordinal age indicators in humans.

If $Q_{i j k}$ is the probability of tooth $j$ of individual $i$ having passed the threshold for the end of stage $k\left(k=1,2, \ldots . N_{j}\right.$ 1 , where $N_{j}$ is the number of stages for tooth $j$ ), then

$$
\operatorname{logit}\left(Q_{i j k}\right)=\delta_{j} \times\left(\ln \left(\theta_{i}\right)-\ln \left(\gamma_{j k}\right)\right)
$$

Where $\operatorname{logit}(Q)=\ln \left(Q /(1-Q), \theta_{i}\right.$ is the individual's age, $\gamma_{j k}$ is the mean threshold age for the tooth and stage in the population, both expressed as years from conception and $\delta_{j}$ is the discriminability, which measures how close together the transitions in the population are. If $\mathrm{p}\left(k_{i j} \mid \theta_{i}\right)$ is the probability of tooth $j$ of individual $i$ being in stage $k$ at age $\theta$, then:

$$
\begin{gathered}
\mathrm{p}\left(1_{\mathrm{ij}} \mid \theta\right)=1-Q_{i j l} \\
\mathrm{p}\left(k_{i j} \mid \theta_{i}\right)=Q_{i j k-1}-Q_{i j k} \text { for } 2 \leq k \leq N_{j}-1 \\
\mathrm{p}\left(N_{i j} \mid \theta_{i}\right)=Q_{i j} N_{j-1}
\end{gathered}
$$

In the case of the two teeth dp4 and P4 the observation of a state of wear on dp4 is conditional on P4 not having erupted. Thus, for dp4 the above equations are modified so that:

$$
\begin{gathered}
\mathrm{p}\left(1_{i, \mathrm{dp} 4} \mid \theta_{i}\right)=\left(1-Q_{i, \mathrm{dp} 4,1}\right) \times \mathrm{p}\left(1_{\mathrm{i}, \mathrm{P} 4} \mid \theta_{i}\right) \\
\mathrm{p}\left(k_{i, \mathrm{dp} 4} \mid \theta_{i}\right)=\left(Q_{i, \mathrm{dp} 4, k-1}-Q_{i, \mathrm{dp} 4, k}\right) \times \mathrm{p}\left(1_{\mathrm{i}, \mathrm{P} 4} \mid \theta_{i}\right) \text { for } 2 \leq k \leq N_{\mathrm{dp} 4}-1 \\
\mathrm{p}\left(N_{i, \mathrm{~m} 3} \mid \theta_{i}\right)=Q_{i, \mathrm{~m} 3, N_{\mathrm{m} 3}-1} \times \mathrm{p}\left(1_{\mathrm{i}, \mathrm{P} 4} \mid \theta_{i}\right)
\end{gathered}
$$

By specifying a joint likelihood for the data, we are able to provide a full probability model for all observable and unobservable quantities (Lunn et al. 2000). If we assume that the wear stages of all the teeth are independent, then:

$$
\mathrm{p}\left(\mathbf{k}_{i} \mid \theta_{i}=\prod_{j} \mathrm{p}\left(\mathrm{k}_{i j} \mid \theta_{i}\right)\right.
$$

Where $\mathbf{k}_{i}$ is the set of observed stages for individual $i$. Note that if the assumption of independence does not hold, then this method will underestimate the uncertainty in age. In order to make inferences about age, we use 
Bayes' theorem to construct the posterior distribution from the observed data.

$$
p\left(\theta_{i} \mid \mathbf{k}_{i}, S\right) \propto \mathrm{p}\left(\mathbf{k}_{i} \mid \theta_{i}\right) \times \mathrm{p}\left(\theta_{i} \mid \mathrm{S}\right)
$$

However, this is entirely conditional on knowing the age structure of the population, $S$. At the population level we may write, using Bayes' theorem again:

$$
\mathrm{p}(\Theta, S \mid \mathbf{K}) \propto \mathrm{p}(\mathbf{K} \mid \Theta, S) \times \mathrm{p}(\Theta, S)
$$

where $\Theta$ is the collection of ages in the population, and $\mathbf{K}$ is the entire set of observed stages in the population. Hence,

$$
\mathrm{p}(\Theta, S \mid \mathbf{K}) \propto \mathrm{p}(\mathbf{K} \mid \Theta) \times \mathrm{p}(\Theta \mid S) \times \mathrm{p}(S)
$$

As the ages of the individuals are independent given $S$,

$$
\mathrm{p}(\Theta, S \mid \mathbf{K}) \propto \prod_{i}\left[\mathrm{p}\left(\mathbf{k}_{i} \mid \boldsymbol{\theta}_{i}\right) \mathrm{p}\left(\theta_{i} \mid S\right)\right] \times \mathrm{p}(S)
$$

In order to apply this model, it is necessary to determine the values of the mean thresholds and the discriminabilities, observe a set of toothwear states, and provide prior probabilities for the possible age structures.

Because the joint posterior distributions in these equations require complex numerical integrations, I use a Markov-chain Monte Carlo (MCMC) method for its evaluation using the WinBUGS program (Spiegelhalter et al. 2000; Lunn et al. 2000).

The code used is available from my website http:// www.dur.ac.uk/a.r.millard/BUGS4Arch.html.

\section{Subsidiary model for reference data}

A modification of the above model is required to handle all of the observations of Deniz and Payne (1982). In some cases they were unable to observe the actual wear stage of a tooth, but instead they report that the tooth is in one of two possible wear stages. This was attributed to the lower light levels in winter and the reduction in light available for examination of the rear cheek teeth. I shall term these "grouped stages". Grouped stages do not occur at random, so simply discarding the data is likely to lead to biased estimated of the transition parameters. We therefore require a mathematical description of how they occur, the parameters of which can be estimated along with the transition parameters.

If a tooth is observed as in either stage $k$ or $k+1$, the observed state is denoted $k^{*}$. Its true state is either $k$ or $k+1$. The probability of being unable to distinguish the two wear stages will depend on the true wear stage, and the time of year, or equivalently the age of the animal (as following Deniz and Payne (1982), the births are all treated as occurring on 1 April). We therefore write:

$$
\mathrm{p}_{\text {obs }}\left(k^{*} \mid k, j\right)=\mathrm{p}_{k, j+} \times \beta \text { and } \mathrm{p}\left(k^{*} \mid k+1, j\right)=\mathrm{p}_{k, j-} \times \beta \text { (3) }
$$

where $\mathrm{p}_{k, j+}$ and $\mathrm{p}_{k, j-}$ represent the probabilities of confusing a stage with the succeeding or preceding one respectively under optimum lighting conditions, and $\beta$ is a parameter to represent the varying effect of lighting conditions. We have no clear idea of how this might vary, but as a first approximation assume that it varies sinusoidally through the year, so that $\beta=\beta_{\text {min }}+\Delta \beta \times\left(1+\sin (\varphi+2 \pi \theta)\right.$, with $\beta_{\text {min }}$, $\Delta \beta$ and $\varphi$ parameters to be estimated. The probability of actually observing stage $k$ is then reduced:

$$
\begin{gathered}
\mathrm{p}_{\mathrm{obs}}\left(k \mid \theta, \mathrm{p}_{k, j+}, \mathrm{p}_{k, j}, \beta\right)=\mathrm{p}\left(k_{i j} \mid \theta_{i}\right)-\mathrm{p}_{\mathrm{obs}}\left(k^{*} \mid k, j\right) \\
-\mathrm{p}_{\mathrm{obs}}\left([k-1]^{*} \mid k, j\right)
\end{gathered}
$$

Using equations 1,2 and 3 , a regression is performed on the data of Deniz and Payne (1982) to determine the unknown $\Gamma_{j}$ (the set of threshold parameters for tooth $j$ ) and $\delta_{\mathrm{j}}$. In this case, Bayes' theorem is written:

$$
\mathrm{p}\left(\Gamma_{\mathrm{j}}, \delta_{\mathrm{j}} \mid \mathbf{K}\right) \propto \mathrm{p}\left(\mathbf{K} \mid \Gamma_{\mathrm{j}}, \delta_{\mathrm{j}}\right) \times \mathrm{p}\left(\Gamma_{\mathrm{j}}\right) \times \mathrm{p}\left(\delta_{\mathrm{j}}\right)
$$

and is used to obtain probability distributions for the parameters, which are summarised in Fig. 1 as means and standard deviations. The priors assumed were uninformative, to express a lack of prior knowledge: the $\gamma_{j k}$ were assumed to be uniformly likely to lie between conception and 13 years after birth, subject to the constraint that they were ordered according to $k$. The other priors were: $\delta_{j} \sim \operatorname{Gamma}(0.01,0.01)$ which constrains $\delta_{j}$ to be positive; $\mathrm{p}_{k, j+} \sim \operatorname{Unif}(0,1)$, and $\mathrm{p}_{k, j-} \sim \operatorname{Unif}(0,1)$ as probabilities must lie between zero and one; $\Delta \beta \sim \operatorname{Unif}(0,1), \beta_{\min } \sim \operatorname{Unif}(0,1-\Delta \beta)$, and $\varphi \sim \operatorname{Unif}(0,2 \pi)$ which simply constrain these parameters to the range of possible values.

\section{Prior distribution for the age structure}

The final element of the model required for its application is the prior $\mathrm{p}(S)$ on the age structure. Clearly, the range of likely age structures must encompass Payne's (1973) idealised structures for milk, meat and wool economies. To represent these as parametric equations would require some terms to represent the natural mortality of sheep, with additional terms to describe the various possibilities for additional mortality from slaughter by humans. Wood et al. (2002) suggest that a model with at least five terms is required to describe natural mortality; it is likely that three more terms would be required to describe agespecific slaughter by humans (one each for mean age, variability of age and intensity of slaughter). Payne (1973) notes four ages when specific economies would require slaughter, and mixed economies might use all of them. An equation with at least 17 parameters is therefore required, and may not be adequate even then. Such a complex model will be difficult to specify and computationally expensive. For this reason, I adopt a discrete non-parametric approach, where the age range from conception to 13 years is approximated by 100 equally-spaced ages, $\mathrm{t}_{\mathrm{a}}(\mathrm{a}=1 . .100)$ and the set of ages of the animals is treated as a multinomial draw from these 100 possible ages. The age structure ISIS is then expressed 


\begin{tabular}{|c|c|c|c|c|c|c|c|c|c|c|c|c|c|c|c|c|}
\hline का: & $\not{\perp}$ & $\vec{\omega}$ & $\bar{N}$ & $\Xi$ & ๘ & 6 & $\infty$ & $\checkmark$ & $a$ & u & 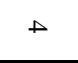 & $\omega$ & N & - & $\begin{array}{l}\text { Stage number (this } \\
\text { studv) }\end{array}$ & \\
\hline & & & & $\boxminus$ & $\stackrel{8}{\circ}$ & 日 & 日 & $\aleph_{\Sigma}^{\infty}$ & $\stackrel{N}{\gtrless}$ & 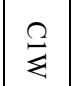 & $\subseteq$ & N & $\pi$ & Е્ટ & $\begin{array}{l}\text { Deniz \& Payne } \\
\text { (1982) symbol }\end{array}$ & \\
\hline & & $\bar{N}$ & ニォ & $\underbrace{\infty}_{0}$ & $\checkmark$ & $a$ & u & 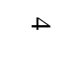 & $\omega$ & N & $-c$ & \pm & $\pi$ & $<$ & $\begin{array}{l}\text { Rowley-Conwy } \\
\text { (1997)code }\end{array}$ & \\
\hline $\mid \begin{array}{l}N \\
\stackrel{N}{H} \\
\stackrel{H}{0} \\
0\end{array}$ & & & 告: & 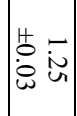 & $\begin{array}{l}40 \\
\dot{0} \dot{0}\end{array}$ & 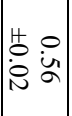 & $\left|\begin{array}{ll}0 & 0 \\
0 & 0 \\
0 & \vdots \\
N & +\end{array}\right|$ & $\begin{array}{l}\text { to } \\
\text { : } \\
\text { i i }\end{array}$ & 告官 & 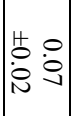 & 蒙: & $\begin{array}{l}140 \\
0 \\
0 \\
0\end{array}$ & $\mid \begin{array}{ll}1 & 0 \\
0 & 0 \\
0 & 0 \\
0 & 0\end{array}$ & 菅: & male threshold & $\frac{2}{8}$ \\
\hline $\begin{array}{l}\overrightarrow{0} \\
\dot{0} \\
\dot{0} \\
\infty\end{array}$ & & & 菅落 & 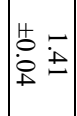 & 蓉: & 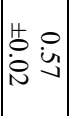 & $\left|\begin{array}{ll}1 & 0 \\
0 & 0 \\
0 & 0 \\
0 & 0\end{array}\right|$ & 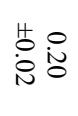 & 告: & $\begin{array}{lll}4 & 0 \\
0 & 0 & 0 \\
0 & 0 & 0\end{array}$ & $\begin{array}{ll}4 & 0 \\
0 & 0 \\
0 & 0 \\
0 & 0\end{array}$ & 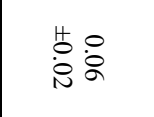 & $\mid$\begin{tabular}{lll}
1 & 0 \\
\hdashline & 0 \\
0 & 0 \\
1 & 0
\end{tabular} & $\begin{array}{l}4 \\
0 \\
0\end{array}$ & female threshold & \\
\hline & & & & & & & & & $\mapsto$ & $\Xi$ & $\subseteq$ & Nt & $\pi$ & & $\begin{array}{l}\text { Deniz \& Payne } \\
\text { (1982) symbol }\end{array}$ & \\
\hline & & & & & 1 & 0 & $\infty$ & $v$ & un & $+N$ & $-c$ & \pm & $\pi$ & $<$ & Rowley-Conwy & \\
\hline 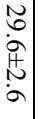 & & & & & & 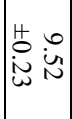 & 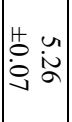 & $\begin{array}{l}4 \\
0 \\
0 \\
0\end{array}$ & 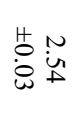 & $\begin{array}{ll}4 & N \\
0 & n \\
0 & 0 \\
0 & 0\end{array}$ & 密灾 & 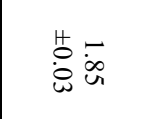 & 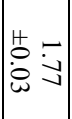 & 蓉 & male threshold & I \\
\hline 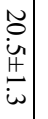 & & & & & & & 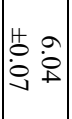 & 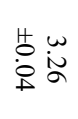 & 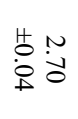 & $\begin{array}{ll}0 & N \\
0 & N \\
0 & 0 \\
0 & 0\end{array}$ & 菅: & 草: & 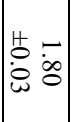 & 范: & female threshold & \\
\hline & के & & 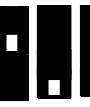 & & & $\square$ & $\square$ & 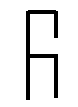 & $\square$ & $\begin{array}{ll}\Pi \\
1\end{array}$ & $\begin{array}{l}11 \\
6 c\end{array}$ & $\begin{array}{l}\text { П I cel } \\
\text { cecece }\end{array}$ & $\subseteq$ & $\underset{ఠ}{\Xi}$ & $\begin{array}{l}\text { Deniz \& Payne } \\
\text { (1982) symbol }\end{array}$ & \\
\hline & 1 & $\Phi$ & $\bar{\omega} \bar{N}$ & $=$ & ๑ 0 & $\infty$ & $\checkmark$ & $a$ & un & $\Delta$ & $\omega$ & N & $-a \mid$ & $\pi \pi<$ & Rowley-Conwy & \\
\hline $\begin{array}{l}\vec{f} \\
\dot{u} \\
\dot{0} \\
0 \\
0\end{array}$ & & $\left|\begin{array}{ll}1 & 0 \\
0 & 0 \\
0 & 0 \\
0 & 0\end{array}\right|$ & $\begin{array}{l}4 \\
0 \\
\dot{N}\end{array}$ & 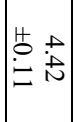 & 告: & \begin{tabular}{ll}
4 & $N$ \\
0 & $N$ \\
0 & $\infty$ \\
\hdashline & $\infty$
\end{tabular} & 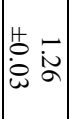 & $\begin{array}{ll}1 & 0 \\
0 & 0 \\
\dot{\omega} & 0 \\
\dot{\omega} & 0\end{array}$ & 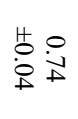 & \begin{tabular}{lll}
4 & 0 \\
\hdashline & 0 \\
\hdashline & $:$ \\
$N$
\end{tabular} & 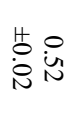 & 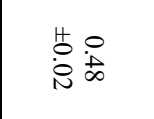 & $\left|\begin{array}{ll}1 & 0 \\
0 & 0 \\
0 & \dot{\omega} \\
& \omega\end{array}\right|$ & $\begin{array}{l}\text { t. } \\
\text { : } \\
\dot{N} \\
\dot{N}\end{array}$ & male threshold & 3 \\
\hline $\begin{array}{l}\overrightarrow{+} \\
\dot{a} \\
\dot{t} \\
\dot{v}\end{array}$ & & & $\begin{array}{l}1 \\
0 \\
\dot{\infty}\end{array}$ & $\left|\begin{array}{ll}4 & + \\
0 & \infty \\
0 & \infty \\
\infty & +\end{array}\right|$ & $\begin{array}{l}4 \\
\dot{0} \\
\dot{2}\end{array}$ & 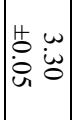 & $\left|\begin{array}{ll}0 & - \\
\hdashline & \vec{\omega} \\
\dot{\omega} & +\end{array}\right|$ & $\begin{array}{l}4 \\
0 \\
0 \\
0\end{array}$ & $\begin{array}{l}1 \\
0 \\
\dot{0} \\
\dot{0}\end{array}$ & 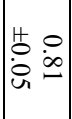 & 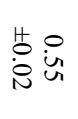 & 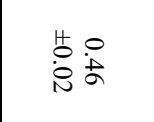 & 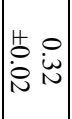 & 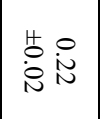 & female threshold & \\
\hline & के & & I & $\square$ & $\square \square$ & $\square$ & $\Pi$ & $\Pi$ & 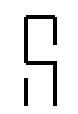 & $\begin{array}{l}1 \\
11\end{array}$ & 11 & $\begin{array}{l}\text { M } 1<1 \\
\text { ceces }\end{array}$ & $\subseteq$ & छ્ઠ & $\begin{array}{l}\text { Deniz \& Payne } \\
\text { (1982) symbol }\end{array}$ & \\
\hline & & 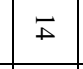 & $\varpi \bar{N}$ & $=$ & 50 & $\infty$ & $\checkmark$ & $a$ & u & A & $\omega$ & N & $-a \mid$ & 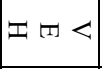 & $\begin{array}{l}\text { Rowley-Conwy } \\
\text { (1997)code }\end{array}$ & \\
\hline $\begin{array}{l}\stackrel{\sim}{u} \\
\dot{H} \\
\dot{H} \\
\infty \\
\infty\end{array}$ & & & $\stackrel{+}{i} \underset{\dot{i}}{\stackrel{i}{w}}$ & $\left|\begin{array}{lll}0 & 0 \\
0 & 0 & 0 \\
\omega & \infty\end{array}\right|$ & 告定 & $\left|\begin{array}{ll}1 & u \\
0 & u \\
0 & \ddot{1}\end{array}\right|$ & 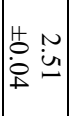 & 告 & : & 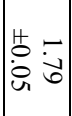 & 告 & 告芯 & $\begin{array}{lll}4 & -1 \\
0 & 0 \\
0 & 0 \\
\end{array}$ & 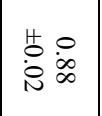 & male threshold & n \\
\hline $\begin{array}{l}\vec{\infty} \\
0 \\
0 \\
0 \\
0\end{array}$ & & & 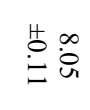 & $\left|\begin{array}{ll}0 & .1 \\
0 & 0 \\
0 & 0\end{array}\right|$ & $\begin{array}{l}1+0 \\
\dot{\infty}\end{array}$ & $\mid \begin{array}{ll}0 & 0 \\
0 & \dot{\tilde{n}} \\
\infty & \infty\end{array}$ & $\left|\begin{array}{ll}1 & N \\
0 & \cdots \\
0 & \infty \\
\perp & \infty\end{array}\right|$ & 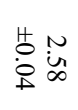 & $\begin{array}{l}\frac{1}{0}: \\
\dot{\omega} \\
\dot{\omega}\end{array}$ & 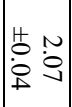 & 告容 & 告芒 & 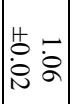 & 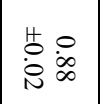 & female threshold & \\
\hline & & & & 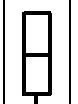 & & $\square$ & $\Pi$ & 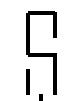 & $\prod_{1}^{1}$ & $\prod$ & 111 & $\begin{array}{l}|c| \\
\operatorname{cec} \mid\end{array}$ & $\subseteq$ & $\underset{\varnothing}{\Xi}$ & $\begin{array}{l}\text { Deniz \& Payne } \\
\text { (1982) symbol }\end{array}$ & \\
\hline & ลे & $\bar{\omega}$ & $\bar{N}=$ & ఠ & 0 & $\infty$ & $\sim$ & $a$ & ur & + & $\omega$ & n & $-a \mid$ & $I \pi<$ & Rowley-Conwy & \\
\hline $\begin{array}{l}\stackrel{N}{N} \\
\stackrel{H}{+} \\
\infty \\
\infty\end{array}$ & 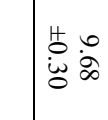 & 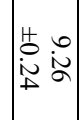 & $\begin{array}{l}0 \\
0 \\
0 \\
0\end{array}$ & 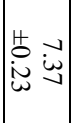 & 菅: & 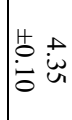 & $\left|\begin{array}{ll}1 & 0 \\
0 & \dot{0} \\
0 & 0\end{array}\right|$ & $\begin{array}{l}4 \\
\dot{0} \\
\dot{0} \\
\dot{0}\end{array}$ & $\begin{array}{l}1 \\
0 \\
0 \\
0\end{array}$ & $\begin{array}{lll}\pi & n \\
0 & 0 \\
0 & 0 \\
0 & 0 \\
\end{array}$ & 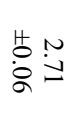 & 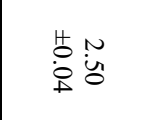 & 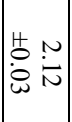 & 范 & male threshold & 3 \\
\hline $\begin{array}{l}\overrightarrow{2} \\
\dot{\hat{\theta}} \\
\dot{0} \\
\dot{0}\end{array}$ & & & 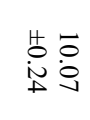 & 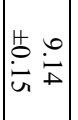 & $\begin{array}{l}4 \\
\dot{0} \\
\dot{\infty} \\
\dot{0}\end{array}$ & 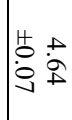 & 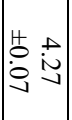 & 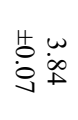 & $\begin{array}{l}0 . \omega \\
0 \\
0\end{array}$ & $\begin{array}{ll}0 & w \\
0 & w \\
0 & 0 \\
ن & 0\end{array}$ & $\begin{array}{l}140 \\
\dot{0} \\
\dot{0}\end{array}$ & 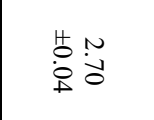 & 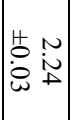 & 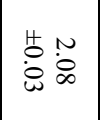 & female threshold & \\
\hline
\end{tabular}


as the set of proportions, $S_{a}$, of the underlying population with ages $\mathrm{t}_{\mathrm{a}}$. A prior for $S$ can then be constructed using a variant of the method of Adcock (1987). If we take Payne's milk and wool curves as two prior estimates of $S$ : $\mathbf{e}_{1}$ and $\mathbf{e}_{2}$, then Adcock shows that a suitable prior for the proportions in $S$ is given by a Dirichlet distribution (a multivariate distribution expressing uncertainty about a set of proportions) with $\mathrm{h}=2\left(1-\sum_{a}^{1 / 2} \eta_{a}^{2}\left(\mathbf{e}_{a}\right) / \sum_{a} \mathbf{e}_{a}\right)$ as the mean prior
estimate, and $d_{a}^{2}$ is the "prior sample size", where $\mathbf{d}=\left(\mathbf{e}_{1}-\mathbf{e}_{2}\right)$. Taking $\mathbf{e}_{1}$ and $\mathbf{e}_{2}$ from Payne's piecewise linear survivorship curves without additional interpolation gives $\mathrm{C}=26$ and a prior with the $95 \%$ confidence range on the survivorship curve shown as a solid line in Fig. 2. However, the range of survivorship curves allowed by this prior is mostly between the Payne milk and wool curves, which is a rather narrow range compared to the variation seen in archaeological assemblages. A prior given by $\mathrm{C}=10$ (Fig. 2 , dotted line) seems more in line with our prior knowledge of the form of $S$.

\section{Results}

\section{Reference population data}

The threshold ages estimated from Deniz and Payne's (1982) data are shown in Fig. 1. The mean ages of transition for females obtained with this method are very close to those illustrated by Deniz and Payne (1982, fig. 24). The discriminabilities for both males and females decrease in the order P4, M2 M3, M1, dp4: this accords with the increases in variability noted by Deniz and Payne. Males are generally earlier than females in their mean transitions, but also exhibit less variability (higher discriminability) than females.

\section{Known age animals test}

There is only a limited amount of published data on the state of wear of the complete set of teeth of individuals of known age suitable for testing the age estimates of the method. Deniz and Payne (1982) give tooth wear data for nine male goats aged 19 or 31 months, and, in addition, O'Connor (1998) gives tooth wear data for 32 modern reference collection sheep aged 5-6 months or 11-12 months (sex is not given). This collection of known age animals is far from a random draw from the age structure of a herd: in both cases, a group of animals has been selected to illustrate the range of variation in the state of the teeth at specific ages. It thus does not make any sense to try to estimate the age structure of the population from the data, and some form for $S$ must be assumed in order to estimate ages. In the case of Deniz and Payne, the animals are drawn from a deliberately constructed pop- ulation with as near as possible the same number of animals in each age class, so an a priori assumption that all ages are equally likely is sensible. In the absence of any other evidence, this is also adopted as a neutral prior for O'Connor's data, though it is not particularly satisfactory.

The results of this test are shown on Fig. 3. Four of the 42 individuals have estimated $95 \%$ confidence ranges that do not include the known age. However, two of them are only just outside the range and we know that the assumption of independence of the state of teeth given age is likely to be violated so that the estimated confidence ranges are too narrow. The nine animals from Deniz and Payne (1982) were of course included in the data used to construct the model, and therefore provide less of a test than the data of O'Connor. The number of mis-aged animals is not too large given the known inadequacy of the model, and the application of goat data to sheep. The data do however illustrate the problem of lack of sex information: the difference in ages for males and females with the same tooth wear state increases with age.

\section{Payne mandible wear stages}

Before examining a case study, it is instructive to consider what this model and transition age estimates imply about the mandible wear stages A-I given by Payne (1973). These are widely used and the equivalent ages given by Payne for these stages are used to compare archaeologically derived survival curves with Payne's three idealised curves for milk, meat and wool economies. Fig. 4 shows the small number of transitions that define Payne's mandible wear stages, and the estimates of the ages of male and female animals falling in each stage using only these transitions and a uniform prior, compared with the ranges given by Payne (1973). It is clear that the commonly used ranges are underestimates of the variability in age of animals in a stage, and that in the latter stages, the ages are underestimated, particularly for females. The age range for the final stage is rather dependent on what is assumed as the absolute upper age limit for sheep or goats (in this case 13 years was assumed).

\section{Case study: Arene Candide}

The Arene Candide data have been analysed twice: once as if all individuals were female and once as if they were all male, as sheep and goat mandibles cannot be sexed. The results for the analyses are shown in Figs 5 and 6. The uncertainty in the survivorship curves is shown as the marginal $95 \%$ confidence limits at each age. It is clear that the bounds on the Early Neolithic survivorship include an idealised milk economy, as well as a variety of intermediate milk-meat economies. The Middle Neolithic I bounds are much more clearly intermediate between the idealised milk and meat economies. In both cases the 


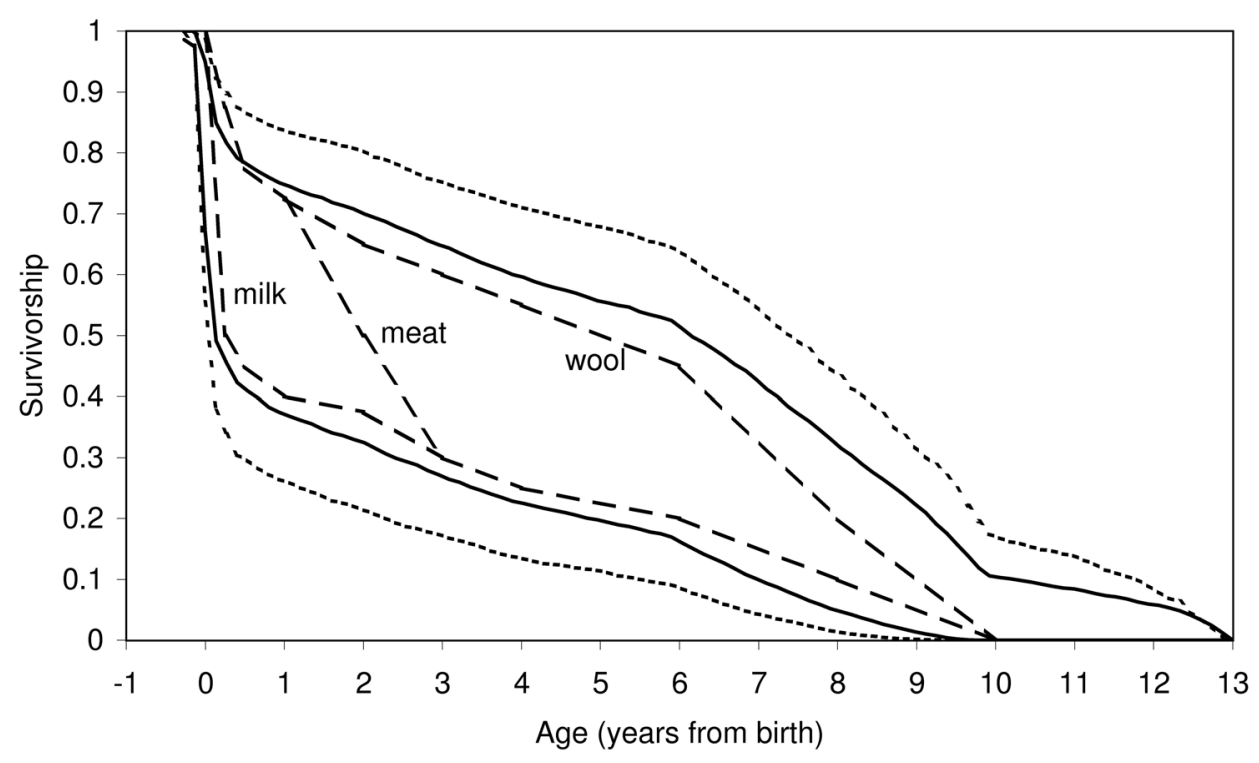

Fig. 2. Prior confidence limits on the survivorship curve. Dashed lines: from top to bottom, Payne's (1973) wool, meat and milk curves. Solid line: prior 95\% confidence limits by method of Adcock (1987). Dotted line: prior 95\% confidence limits adopted here.

survivorship falls off faster than would be predicted by any of the ideal curves once past the age of five or so. The Early Neolithic curve is significantly different from that derived by Rowley-Conwy using traditional methods and shows the effect of removing the under-ageing of those methods.

Both data-sets show that there are differences in the result depending on the sex of the animals. As the sex ratio is expected to vary with age in different ways with different economies, it is not possible to assume one sex ratio and adjust the spread of possible survivorship curves for the uncertain sex of each animal. Some data on the variation of sex ratio with age is needed. It might be sufficient to assume the sex ratio at birth and know the average adult sex ratio in order to do this, but more work would be needed to develop suitable statistical models.

There are distinct sections of all curves that show a rapid fall in survivorship, which could be interpreted as age-specific slaughter. However, if there is covariance in the ages of transition, and if there is a bunching of transitions in different teeth in a short age-span, then, when the transitions are treated as independent, there will be an underestimate of uncertainty which biases ages to fall one side or the other of the bunch of transitions. Such an effect could be causing the rapid falls in survivorship and demonstrate one of the fundamental weaknesses of having to assume independence because there are no data on covariance. If one were able to estimate the mean thresholds from the tooth wear states of individuals, it would be possible to allow for covariance of tooth wear stages. Hence, it must be concluded that even better reference data are needed than those of Deniz and Payne (1982). The data of Jones (this volume) look promising in that regard, and would also allow different age estimations to be established for sheep and goats.

The prior on the survivorship curve adopted here is only a crude approximation of our prior knowledge. A more realistic prior might be constructed by considering what range of kill profiles are compatible with maintaining herd reproductive potential, for example, using the simulation methods of Cribb (1985).

\section{Conclusions}

This paper has shown that the statistical methods underlying skeletal ageing techniques for animals need to be overhauled. The proposed technique of transition analysis using Bayesian statistical models shows that this can be done. The examples analysed here show that there is great uncertainty in ageing of animals, especially as that shown here is certainly an underestimate. More work is needed to incorporate sex ratios into the estimation of survivorship curves. The methods presented have also ignored taphonomic biases: I have assumed that we have a representative sample of the target population. To consider taphonomic processes will require appropriate statistical models to incorporate into the analysis the additional uncertainty which they bring. Rogers (2000) method for 'Analysis of Bone Counts' is promising in this regard, but it demands carefully observed and recorded actualistic data of a type not widely available at the moment.

\section{Acknowledgements}

I am grateful to Peter Rowley-Conwy for supplying me 


\begin{tabular}{|c|c|c|c|c|c|c|c|c|c|c|}
\hline \multirow{2}{*}{$\begin{array}{l}\text { Age } \\
\text { (months) }\end{array}$} & \multirow{2}{*}{$\begin{array}{l}\text { Age } \\
\text { (years) }\end{array}$} & & \multirow[t]{2}{*}{ Ref } & \multicolumn{5}{|c|}{ toothwear stage $^{\#}$} & \multicolumn{2}{|c|}{$\mathbf{9 5 \%}$ confidence interval for age (years) } \\
\hline & & & & dp4 & P4 & M1 & M2 & M3 & female & male \\
\hline 5 & 0.42 & * & 1 & 10 & NA & 5 & 1 & 1 & $0.49-0.92$ & $0.47-0.87$ \\
\hline 5.5 & 0.46 & & 1 & 9 & NA & 5 & 1 & 1 & $0.40-0.81$ & $0.37-0.76$ \\
\hline 5.5 & 0.46 & & 1 & 9 & $\mathrm{NA}$ & 3 & 1 & 1 & $0.28-0.61$ & $0.28-0.61$ \\
\hline 5.6 & 0.47 & & 1 & 8 & $\mathrm{NA}$ & 3 & 1 & 1 & $0.21-0.53$ & $0.21-0.51$ \\
\hline 5.6 & 0.47 & & 1 & 9 & NA & 5 & 1 & 1 & $0.40-0.81$ & $0.37-0.75$ \\
\hline 5.75 & 0.48 & & 1 & 9 & NA & 3 & 1 & 1 & $0.27-0.61$ & $0.28-0.60$ \\
\hline 5.75 & 0.48 & & 1 & 9 & $\mathrm{NA}$ & 4 & 1 & 1 & $0.34-0.68$ & $0.33-0.66$ \\
\hline 5.8 & 0.48 & & 1 & 9 & $\mathrm{NA}$ & 3 & 1 & 1 & $0.28-0.61$ & $0.28-0.61$ \\
\hline 5.8 & 0.48 & & 1 & 9 & NA & 3 & 1 & 1 & $0.27-0.61$ & $0.28-0.61$ \\
\hline 5.8 & 0.48 & & 1 & 9 & NA & 3 & 1 & 1 & $0.28-0.61$ & $0.28-0.61$ \\
\hline 5.8 & 0.48 & & 1 & 9 & NA & 3 & 1 & 1 & $0.28-0.62$ & $0.28-0.61$ \\
\hline 5.8 & 0.48 & & 1 & 10 & NA & 3 & 1 & 1 & $0.31-0.75$ & $0.35-0.77$ \\
\hline 5.8 & 0.48 & & 1 & 8 & $\mathrm{NA}$ & 3 & 1 & 1 & $0.22-0.53$ & $0.21-0.51$ \\
\hline 5.8 & 0.48 & & 1 & 8 & NA & 3 & 1 & 1 & $0.22-0.53$ & $0.21-0.51$ \\
\hline 5.9 & 0.49 & & 1 & 8 & NA & 3 & 1 & 1 & $0.21-0.53$ & $0.21-0.51$ \\
\hline 6 & 0.50 & & 1 & NA & NA & 4 & 1 & 1 & $0.31-0.76$ & $0.31-0.75$ \\
\hline 6 & 0.50 & & 1 & 10 & $\mathrm{NA}$ & 5 & 1 & 1 & $0.49-0.92$ & $0.47-0.87$ \\
\hline 6 & 0.50 & & 1 & 9 & $\mathrm{NA}$ & 6 & 1 & 1 & $0.47-0.91$ & $0.42-0.82$ \\
\hline 6 & 0.50 & & 1 & 8 & NA & 4 & 1 & 1 & $0.27-0.63$ & $0.25-0.59$ \\
\hline 11 & 0.92 & & 1 & 9 & NA & 6 & 1 & 1 & $0.46-0.92$ & $0.42-0.82$ \\
\hline 11 & 0.92 & & 1 & 9 & $\mathrm{NA}$ & 8 & 1 & 1 & $0.51-1.07$ & $0.46-0.96$ \\
\hline 11 & 0.92 & & 1 & 10 & NA & 8 & 1 & 1 & $0.67-1.18$ & $0.63-1.05$ \\
\hline 11 & 0.92 & $*$ & 1 & 10 & NA & 10 & 3 & 1 & $1.03-1.75$ & $0.97-1.45$ \\
\hline 11 & 0.92 & & 1 & 10 & $\mathrm{NA}$ & 9 & 1 & 1 & $0.69-1.32$ & $0.66-1.13$ \\
\hline 12 & 1.00 & & 1 & 12 & NA & 9 & 1 & 1 & $0.88-1.60$ & $0.80-1.36$ \\
\hline 12 & 1.00 & & 1 & 10 & NA & 8 & 1 & 1 & $0.66-1.18$ & $0.63-1.05$ \\
\hline 12 & 1.00 & & 1 & 10 & $\mathrm{NA}$ & 6 & 1 & 1 & $0.59-1.00$ & $0.54-0.90$ \\
\hline 12 & 1.00 & & 1 & 10 & $\mathrm{NA}$ & 8 & 1 & 1 & $0.66-1.19$ & $0.63-1.05$ \\
\hline 12 & 1.00 & * & 1 & 11 & $\mathrm{NA}$ & 9 & 3 & 1 & $1.07-1.60$ & $1.01-1.41$ \\
\hline 12 & 1.00 & & 1 & 10 & $\mathrm{NA}$ & 9 & 3 & 1 & $1.00-1.53$ & $0.95-1.37$ \\
\hline 12 & 1.00 & & 1 & 10 & NA & 9 & 3 & 1 & $0.99-1.52$ & $0.95-1.37$ \\
\hline 12 & 1.00 & $*$ & 1 & 11 & $\mathrm{NA}$ & 9 & 3 & 1 & $1.06-1.60$ & $1.01-1.42$ \\
\hline 19.5 & 1.63 & & 2 & 13 & NA & 9 & 5 & 1 & $1.50-2.24$ & $1.33-1.81$ \\
\hline 19.5 & 1.63 & & 2 & 13 & $\mathrm{NA}$ & 9 & 6 & 1 & $1.66-2.39$ & $1.49-1.93$ \\
\hline 19.5 & 1.63 & & 2 & 13 & $\mathrm{NA}$ & 9 & 5 & 1 & $1.50-2.24$ & $1.33-1.82$ \\
\hline 19.5 & 1.63 & & 2 & 13 & $\mathrm{NA}$ & 9 & 5 & 1 & $1.49-2.24$ & $1.32-1.82$ \\
\hline 19.5 & 1.63 & & 2 & 13 & NA & 9 & 5 & 1 & $1.50-2.23$ & $1.33-1.82$ \\
\hline 31.5 & 2.63 & & 2 & NA & 6 & 10 & 9 & 5 & $2.70-3.61$ & $2.43-3.01$ \\
\hline 31.5 & 2.63 & & 2 & NA & 7 & 11 & 9 & 5 & $2.92-3.87$ & $2.58-3.19$ \\
\hline 31.5 & 2.63 & & 2 & NA & 7 & 10 & 9 & 4 & $2.77-3.59$ & $2.49-3.04$ \\
\hline 31.5 & 2.63 & & 2 & NA & 6 & 9 & 9 & 3 & $2.34-3.08$ & $2.24-2.73$ \\
\hline
\end{tabular}

Fig. 3. Comparison of age estimates with ages of known age animals. References: 1 - O'Connor (1998); 2 - Deniz and Payne (1982). NA = not observed. * = discrepancy between estimated and known ages \# refer to column 1 of Fig. 1 and read across to find Deniz and Payne (1982) or Rowley-Conwy (1997) equivalents.

\begin{tabular}{|c|c|c|c|c|}
\hline Stage & Payne (1973) range (years) & Defining state \# & Male 95\% confidence range & Female 95\% confidence range \\
\hline A & $0-0.17$ & $\mathrm{dp} 4<5$ & $-0.39-0.11$ & \\
\hline $\mathrm{B}$ & $0.17-0.5$ & $\mathrm{dp} 4>4, \mathrm{M} 1<3$ & $0.01-0.36$ & $-0.39-0.16$ \\
\hline $\mathrm{C}$ & $0.5-1$ & $\mathrm{M} 1>2, \mathrm{M} 2<3$ & $0.33-1.25$ & $0.01-0.44$ \\
\hline $\mathrm{D}$ & $1-2$ & $\mathrm{M} 2>2, \mathrm{M} 3<3$ & $0.92-2.22$ & $1.00-2.49$ \\
\hline $\mathrm{E}$ & $2-3$ & $2<\mathrm{M} 3<7$ & $1.98-3.37$ & $2.04-4.27$ \\
\hline $\mathrm{F}$ & $3-4$ & $6<\mathrm{M} 3<11$ & $2.92-4.84$ & $3.26-5.86$ \\
\hline $\mathrm{G}$ & $4-6$ & $\mathrm{M} 2=9, \mathrm{M} 3=11$ & $4.15-6.67$ & $5.32-7.28$ \\
\hline $\mathrm{H}$ & $6-8$ & $\mathrm{M} 2>9, \mathrm{M} 3=11$ & $4.96-8.03$ & $8.25-12.52$ \\
\hline $\mathrm{I}$ & $8-10$ & $\mathrm{M} 3>11$ & $7.22-12.87$ & \\
\hline
\end{tabular}

Fig. 4 Estimated ages (in years from birth) for animals in Payne mandible wear stages A-I. \# numerical states refer to column 1 of Fig. 1 and read across to find Deniz and Payne (1982) or Rowley-Conwy (1997) equivalents. 


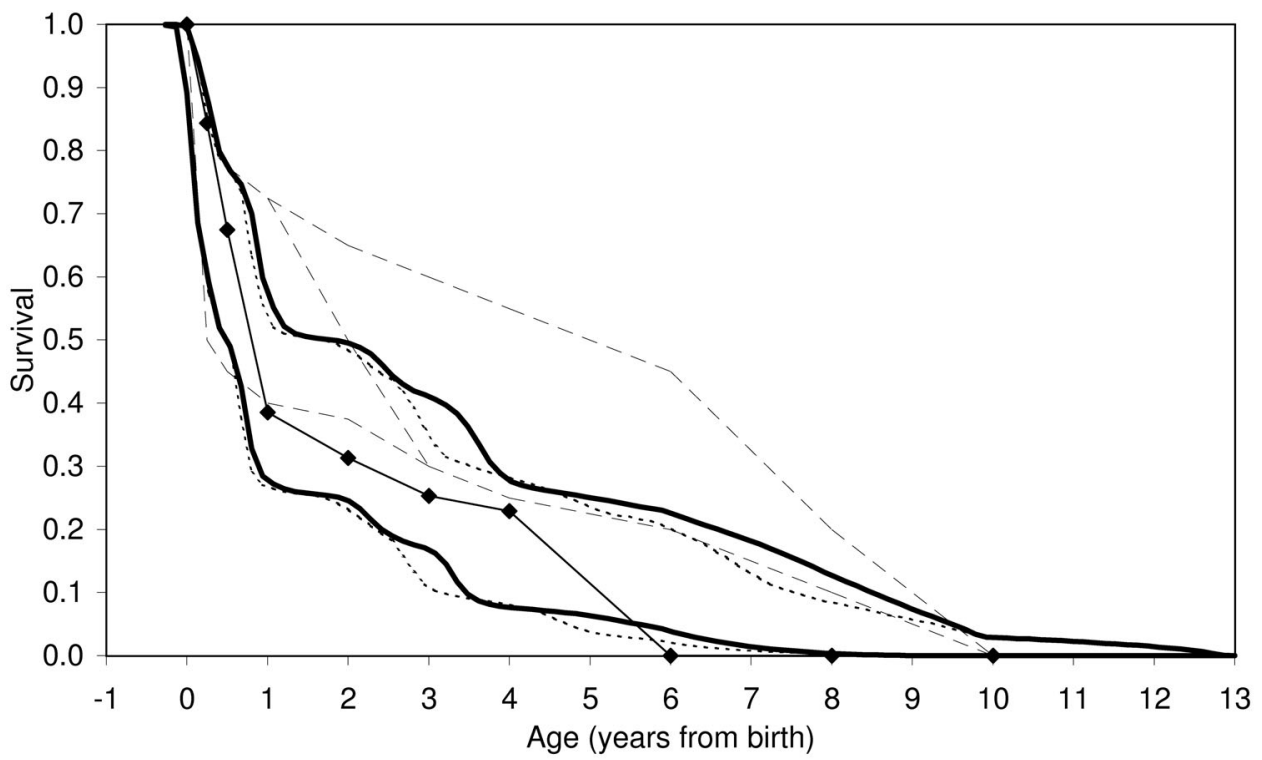

Fig. 5. Survivorship curves for the Early Neolithic sheep and goats at Arene Candide. Key: Dashed lines: Payne idealised curves as in Fig. 2. Thin solid line with diamonds: Rowley-Conwy's (1997) curve. Solid line: posterior $95 \%$ confidence interval if all individuals are female. Dotted line: posterior 95\% confidence interval if all individuals are male.

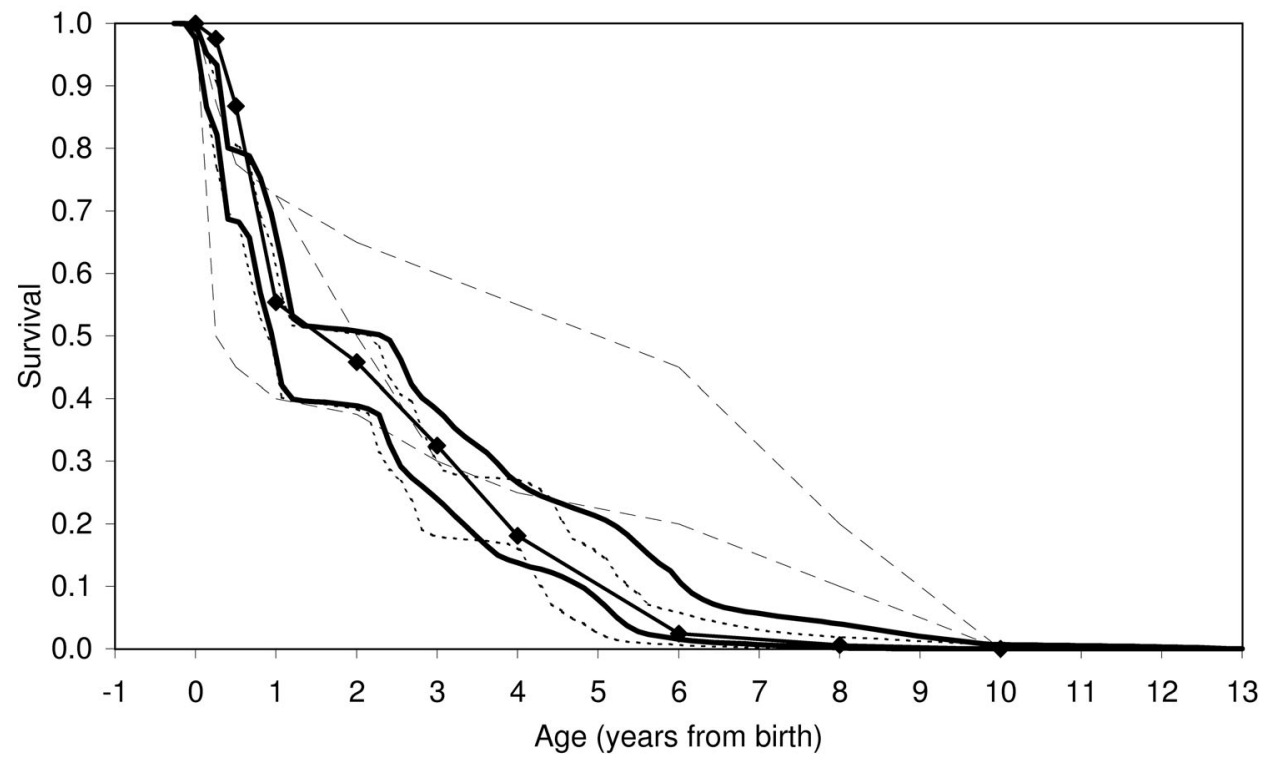

Fig. 6. Survivorship curves for the Middle Neolithic I sheep and goats at Arene Candide. Key: as Fig. 5.

with the Arene Candide data, and to Gill Jones for extensive discussion of the issues of ageing sheep from toothwear. Gill Jones and Caitlin Buck provided helpful comments on an earlier draft. Gill Jones also suggested the term "grouped stages". Finally, thanks to Deborah Ruscillo for all her work in organising an excellent conference session and editing this volume.

\section{References}

Adcock, C. 1987. A Bayesian approach to calculating sample sizes for multinomial sampling. The Statistician 36, 155-9.

Aykroyd, R. G., Lucy, D., Pollard, A. M. and Solheim, T. 1997. Technical note: Regression analysis in adult age estimation. American Journal of Physical Anthropology 104, 259-65.

Aykroyd, R. G., Lucy, D., Pollard, A. M. and Roberts, C. A. 1999. Nasty, brutish, but not necessarily short: a reconsideration of the statistical methods used to calculate age at death from adult 
human skeletal and dental age indicators. American Antiquity 64, 55-70.

Blaxter, K. L. (ed.) 1980. The nutrient requirements of ruminant livestock. Wallingford: $\mathrm{CAB}$ International.

Bocquet-Appel, J-P. and Masset, C. 1982. Farewell to palaeodemography. Journal of Human Evolution 11, 321-333.

Bocquet-Appel, J. P. and Masset, C. 1985. Palaeodemography: resurrection or ghost? Journal of Human Evolution 14, 107111.

Bocquet-Appel, J. P. and Masset, C. 1996. Palaeodemography: expectancy and false hope. American Journal of Physical Anthropology 99, 571-584.

Boldsen J. L., Milner, G. R., Konigsberg, L.W. and Wood, J. W. 2002. Transition analysis: a new method for estimating age from skeletons, pp. 73-106 in Hoppa, R. D. and Vaupel, J. W. (eds), Paleodemography: age distributions from skeletal samples. Cambridge: Cambridge University Press.

Chamberlain, A. T. 2000. Problems and prospects in palaeodemography, pp. 101-15, in Cox, M. and Mays, S. (eds), Human Osteology in Archaeology and Forensic Science. London: Greenwich Medical Media.

Cribb, R. 1985. The analysis of ancient herding systems: an application of computer simulation in faunal studies, pp. 75106, in Barker, G. and Gamble, C. (eds), Beyond Domestication in Prehistoric Europe: Investigations in Subsistence Archaeology and Social Complexity. London: Academic Press.

Dahl, G. and Hjort, A. 1976. Having herds: pastoral herd growth and household economy. (Stockholm Studies in Social Anthropology 2). Stockholm: University of Stockholm Department of Social Anthropology.

Deniz E. and Payne S. 1982 Eruption and wear in the mandibular dentition as a guide to ageing Turkish Angora goats, pp.155205, in Wilson, B., Grigson, C. and Payne, S. (eds), Ageing and sexing animal bones from archaeological sites. Oxford: British Archaeological Reports.

Halstead, P., Collins, P. and Isaakidou, V. 2002. Sorting the sheep from the goats: Morphological distinctions between the mandibles and mandibular teeth of adult Ovis and Capra, Journal of Archaeological Science 29, 545-553.

Hillson, S. 1986. Teeth. Cambridge: Cambridge University Press.

Holman, D. J., Wood, J. W. and O'Connor, K. A. 2002. Estimating age-at-death distributions from skeletal samples: a multivariate latent-trait approach, pp.193-221, in Hoppa R. D. and Vaupel J. W. (eds) Paleodemography: Age Distributions from Skeletal Samples. Cambridge Studies in Biological and Evolutionary Anthropology 31. Cambridge University Press.

Hoppa, R. D. and Vaupel, J. W. 2002. The Rostock Manifesto for paleodemography: the way from stage to age, pp.1-8, in Hoppa, R. D. and Vaupel, J. W. (eds) Paleodemography: Age Distributions from Skeletal Samples. Cambridge Studies in Biological and Evolutionary Anthropology 31. Cambridge University Press.

Jones, G. 1992. Animal and bird bone, pp. 176-191 in Dallas, C. (ed.), Excavations in Thetford by B. K. Davison between 1964 and 1970. (East Anglian Archaeology Report 62). Dereham: Norfolk Museums Service and The Scole Archaeological Committee.

Jones, G. G. (2006) Tooth eruption and wear observed in live sheep from Butser Hill, the Cotswold Farm Park and five farms in the Pentland Hills. This volume.

Konigsberg, L. W. and Frankenberg, S. R. 1992. Estimation of age structure in anthropological demography. American Journal of Physical Anthropology 89, 235-256.

Konigsberg, L. W. and Frankenberg, S. R. 1994. Palaeodemography: "Not quite dead". Evolutionary Anthropology 3, 92-105.

Konigsberg, L. W., Frankenberg, S. R. and Walker, R. B. 1997. Regress what on what?: Palaeodemographic age estimation as a calibration problem, pp. 64-88, in Paine, R. R. (ed.), Integrating
Archaeological Demography: Multidisciplinary Approaches to Prehistoric Populations (Center for Archaeological Investigations, Occasional Paper No. 24). Carbondale: Southern Illinois University.

Konigsberg, L. W. and Holman, D. 1999. Estimation of age at death from dental emergence and implications for studies of prehistoric somatic growth, pp. 264-289, in Hoppa, R. D. and Fitzgerald, C. M. (eds), Human Growth in the Past. Cambridge: Cambridge University Press.

Konigsberg, L. W. and Herrman, N. P. 2002. Markov-chain MonteCarlo estimation of hazard model parameters in palaeodemography, pp.222-242, in Hoppa, R. D. and Vaupel, J. W. (eds), Paleodemography: age distributions from skeletal samples. Cambridge: Cambridge University Press.

Love, B. and Müller, H.-G. 2002. A solution to the problem of obtaining a mortality schedule for paleodemographic data, pp.181-192, in Hoppa, R. D. and Vaupel, J. W. (eds), Palaeodemography: age distributions from skeletal samples. Cambridge: Cambridge University Press.

Lucy, D. 1997. Human Age Estimation from Skeletal and Dental Evidence. Unpublished Ph.D. thesis, University of Bradford.

Lucy, D., Aykroyd, R. G., Pollard, A. M. and Solheim, T. 1996. A Bayesian approach to adult human age estimation from dental observations by Johanson's age changes. Journal of Forensic Sciences 41, 189-194.

Lunn, D. J., Thomas, A., Best, N. and Spiegelhalter, D. 2000. WinBUGS - A Bayesian modelling framework: concepts, structure, and extensibility. Statistics and Computing 10, 325337.

Millard A. R. and Gowland R. L. 2002. A Bayesian approach to the estimation of the age of humans from tooth development and wear. Archeologia e Calcolatori 13, 197-210.

Moran, N. C. and O'Connor, T. P. 1994. Age attribution in domestic sheep by skeletal and dental maturation: a pilot study of available sources. International Journal of Osteoarchaeology 4, 267285.

O'Connor, T. P. 1991. Bones from 46-54 Fishergate (The Archaeology of York 15, 4). London: Council for British Archaeology.

O'Connor, T. P. 1998. On the difficulty of detecting seasonal slaughtering of sheep. Environmental Archaeology 3, 5-11.

Payne, S. 1973. Kill-off patterns in sheep and goats: the mandibles from Aşvan Kale. Anatolian Studies 33, 281-303.

Payne, S. 1985. Morphological distinctions between the mandibular teeth of young sheep, Ovis, and goats, Capra. Journal of Archaeological Science 12, 139-147.

Rogers, A. R. 2000. Analysis of bone counts by maximum likelihood. Journal of Archaeological Science 27, 111-126.

Rowley-Conwy, P. 1997. The animal bones from Arene Candide: final report, pp.154-277, in Maggi, R. (ed.), Arene Candide: a functional and environmental assessment of the Holocene sequence (excavations Bernabò Brea-Cardini 1940-50). Rome: Il Calamo.

Spiegelhalter, D., Thomas, A., and Best, N. 2000. WinBUGS Version 1.3 User Manual, Cambridge: MRC Biostatistics Unit. http:// www.mrc-bsu.cam.ac.uk/bugs

Wood, J. W., Holman, D. J., O'Connor, K. A. and Ferrell, R. J. 2002. Mortality models for paleodemography, pp.129-168, in Hoppa, R. D. and Vaupel, J. W. (eds), Paleodemography: Age Distributions From Skeletal Samples. Cambridge Studies in Biological and Evolutionary Anthropology 31. Cambridge University Press.

\section{Andrew Millard}

Department of Archaeology

University of Durham

South Road

Durham

DH1 3LE 